\title{
Mereduksi Potensi Gangguan Psikososial Anak melalui Optimalisasi Pengetahuan Ibu tentang Stunting
}

\author{
Ira Kusumawaty ${ }^{*}$, Yunike $^{2}$, Podojoyo ${ }^{3}$ \\ ${ }^{1}$ Departemen Keperawatan Jiwa, Jurusan Keperawatan, Poltekkes Palembang \\ ${ }^{2}$ Departemen Keperawatan Anak, Jurusan Keperawatan, Poltekkes Palembang \\ ${ }^{3}$ Departemen Gizi, Jurusan Gizi, Poltekkes Palembang \\ *Correspondent Author: irakusumawaty@poltekkespalembang.ac.id
}

\begin{abstract}
ABSTRAK
Kejadian stunting masih menghantui anak sebagai investasi bangsa dan jika tidak segera direduksi maka gangguan psikososial dapat menyerang anak pada pertumbuhan dan perkembangan selanjutnya. Peran urgen ibu dalam melakukan upaya preventif, promotif terhadap stunting harus dioptimalkan sesegera mungkin, agar pertumbuhan dan perkembangan anak berjalan optimal. Namun demikian, masih minim pemahaman ibu mengenai stunting dan akibat buruknya yang dapat mengakibatkan terjadinya gangguan psikososial. Kegiatan pengabdian ini bertujuan meningkatkan pemahaman ibu dalam mengenal, mencegah stunting dan serta melakukan upaya perbaikan kondisi pada anak yang sudah mengalami stunting. Metoda ceramah, tanya jawab, diskusi dan demonstrasi disertai media video, slide serta flipchart digunakan dalam kegiatan pengabdian ini. Hasil kegiatan penyuluhan memberikan peningkatan rata-rata nilai pemahaman ibu mengenai stunting serta gangguan psikososial akibat tidak diatasinya stunting, meningkat dari 26 menjadi 69. Kegiatan penyuluhan bagi ibu yang memiliki balita mampu mengoptimalkan pemahaman ibu tentang dampak gangguan psikosial akibat stunting, cara mencegah serta upaya memenuhi kebutuhan kecukupan gizi anak. Dibutuhkan pendampingan dan pengawasan oleh kader kesehatan terhadap kondisi kesehatan anak agar tidak terjadi peningkatan jumlah stunting dan dapat memantau ketertinggalan pertumbuhan dan perkembangan anak yang sudah mengalami stunting.
\end{abstract}

Kata Kunci: Gangguan Psikososial, Pengetahuan Ibu, Stunting

Received: July 8, 2021

Revised: August 10, 2021

Accepted: September 1, 2021

This is an open-acces article distributed under the terms of the Creative Commons Attribution-ShareAlike 4.0 International License.

\section{PENDAHULUAN}

Stunting merupakan gangguan pertumbuhan fisik yang ditandai dengan penurunan kecepatan pertumbuhan dan merupakan dampak dari ketidakseimbangan gizi. Ibu memegang peranan penting dalam mendukung upaya mengatasi masalah gizi, terutama dalam hal asupan gizi keluarga, mulai dari penyiapan makanan, pemilihan bahan makanan, sampai menyiapkan menu makanan. Persentase balita pendek di Indonesia masih tinggi dan merupakan masalah kesehatan yang harus ditanggulangi. Dibandingkan beberapa negara 


\section{Journal of Community Engagement in Health}

http://jceh.org

https://doi.org/10.30994/jceh.v4i2.238

ISSN: 2620-3758 (print); 2620-3766 (online)

Vol. 4 No 2. Sep 2021. Page. 269-274

tetangga, prevalensi balita pendek di Indonesia juga tertinggi dibandingkan Malaysia, Myanmar, Singapura, Vietnam dan Thailand (Kemenkes RI, 2016). Kemampuan keluarga dalam memenuhi kebutuhan pangan baik dalam jumlah maupun mutu gizinya sangat berpengaruh bagi status gizi anak. Ibu yang memiliki status gizi baik akan melahirkan anak yang bergizi baik.

Asupan zat gizi yang optimal menunjang tumbuh kembang balita baik secara fisik, psikis, maupun motorik, asupan zat gizi yang optimal pada saat ini merupakan gambaran pertumbuhan dan perkembangan yang optimal pula di hari depan (Schneider \& Gurovich, 2017). Pengembangan anak usia dini sangat penting dalam investasi sumber daya manusia (Wille et al., 2008). Sebaliknya, anak tunagrahita berisiko memiliki prestasi sekolah yang buruk, produktivitas yang rendah, lebih banyak anak dengan gangguan perkembangan masa pengasuhan, oleh karena itu, menyebabkan transmisi kemiskinan lintas generasi (Himaz, 2018). Gangguan perkembangan, terutama dalam aspek motorik kasar, dapat dimulai pada tahun pertama kehidupan (Valla et al., 2015). Keterlambatan perkembangan dalam setidaknya dua domain denda atau motorik kasar, bahasa, kognitif, sosial, dan aktivitas sehari-hari mempengaruhi anak berusia di bawah lima tahun dalam skala global (Mithyantha et al., 2017). Anak stunting telah digunakan sebagai indikator terjadinya gangguan perkembangan (Brown \& Pollitt, 1996).

Stunting merupakan gangguan pertumbuhan yang dapat mengindikasikan adanya gangguan pada organ-organ tubuh, dimana salah satu organ yang paling cepat mengalami kerusakan pada gangguan gizi ialah otak (Picauly \& Toy, 2013). Masalah ini menjadi krusial setelah diketahui bahwa stunting dapat mempengaruhi mental anak. Ada berbagai bukti menunjukkan stunting berkontribusi terhadap aspek motorik dan gangguan psikososial. Anak stunting dapat memiliki masalah psikologis seperti: kepuasan sendiri mengenai tinggi badan, dan kecenderungan diperlakukan seolah-olah mereka lebih muda dari usia mereka, diganggu, atau diejek (Erling, 2004). Selanjutnya, gangguan psikososial yang merugikan juga dapat berlanjut hingga masa remaja dimana tinggi badan dapat mempengaruhi efikasi diri dan interaksi teman sebaya (Himaz, 2018).

Pada tahap selanjutnya jika tidak diatasi dengan segera, maka gangguan psikososial akibat stunting berlanjut pada masa remaja (Lee et al., 2009). Beberapa faktor risiko telah ditemukan terkait dengan disfungsi psikososial pada remaja stunting seperti jenis kelamin, pendidikan ibu dan ayah yang lebih rendah, kurangnya pendapatan keluarga dan kemiskinan (Wille et al., 2008). Tingkat pendidikan orang tua yang rendah dan kemiskinan dapat membahayakan kesehatan psikososial remaja melalui paparan berbagai kesulitan, dan ini mungkin termasuk stres orang tua, kurangnya kehangatan dan cinta (Costello et al., 2001). Remaja stunting rentan mengalami gangguan psikososial pada tiga aspek (internalisasi, eksternalisasi dan atensi). Mereka sering merasa terasing dalam komunitas sosialnya, memiliki persepsi negatif, menarik diri secara sosial, rendah diri, dan sering depresi dengan menjadi sasaran ejekan teman-temannya (Voss \& Sandberg, 2004).

Berdasarkan informasi yang diperoleh dari pemegang program puskesmas di puskesmas 1 Ulu Palembang, terdapat beberapa warganya yang mengalami stunting. Diketahui pula bahwa di daerah mitra, pada umumnya warga berada pada kondisi sosial ekonomi menengah ke bawah, umunya bekerja sebagai buruh dan berlatar belakang pendidikan rendah. Rendahnya pengetahuan ibu juga diketahui bahwa pada saat diwawancarai, 3 orang ibu menyatakan stunting merupakan penyakit keturunan dan tidak bisa diperbaiki kondisinya. Padahal masalah stunting dinilai tidak hanya masalah kekurangan gizi atau makanan, dapat juga berkaitan dengan konsumsi air, tempat sanitasi dan tempat pembuangan sampah. 


\section{Journal of Community Engagement in Health}

http://jceh.org

https://doi.org/10.30994/jceh.v4i2.238

ISSN: 2620-3758 (print); 2620-3766 (online)

Vol. 4 No 2. Sep 2021. Page. 269-274

\section{BAHAN DAN METODE}

Pelaksanaan penyuluhan bertujuan mengoptimalkan pemahaman ibu tentang beberapa komponen terkait stunting, termasul cara pencegahan dan dampak yang ditimbulkannya. Kegiatan ini telah dilaksanakan pada tanggal 5 April 2021 bertempat di ruang penyuluhan Puskesmas 1 Ulu Palembang. Kegiatan berlangsung selama 4 jam, dari pukul 08.00-12.00 WIB, diikuti oleh $17 \mathrm{ibu}$ yang memiliki anak berusia balita. Acara penyuluhan diawali dengan pembukaan oleh kepala puskesmas, kemudian dilanjutkan dengan pengukuran tinggi badan dan berat badan balita. Setelah pengukuran dan pencatatan selesai, dilanjutkan dengan penyuluhan mengenai stunting, meliputi: definisi, penyebab dan dampak stunting bagi anak. Beberapa alat bantu digunakan dalam pelaksanaan penyuluhan termasuk media video, slide, flipchart. Pada saat penyuluhan, para kader kesehatan turut mendampingi ibuibu peserta penyuluhan hingga acara usai.

Ibu merupakan ujung tombak dalam menentukan kondisi kesehatan keluarga, terutama anak. Agar ibu dapat memberikan nutrisi yang tepat bagi anak, maka diperlukan penyuluhan sebagai salah satu cara dalam mengupayakan optimalisasi preventif dan promotif. Kegiatan ini dilaksanakan dalam 3 tahap yaitu: persiapan, pelaksanaan dan evaluasi.

Pada tahap persiapan, pengabdi mempersiapkan aspek administrasi, termasuk menyebarkan undangan, ruangan, alat bantu atau media yang akan digunakan serta bahan makanan yang akan dimasak dan selanjutnya dibagikan kepada para ibu. Persiapan ini dilaksanakan bersama petugas puskesmas yang menjadi pemegang program. Kegiatan persiapan ini dilaksanakan satu hari sebelum pelaksanaan.

Pada hari kedua, dilakukan pengolahan makanan di pagi hari bersama petugas puskesmas, hasil olahan tersebut akan dijadikan sebagai contoh makanan yang sehat dan akan diberikan kepada peserta penyuluhan. Setelah makanan siap untuk dihidangkan, acara dilanjutkan dengan acara pembukaan penyuluhan oleh kepala puskesmas. Pada saat pembukaan, disampaikan pentingnya pelaksanaan penyuluhan untuk mencegah terjadinya stunting, cara mengatasi stunting yang sedang dialami serta mengoptimalkan pertumbuhan dan perkembangan hingga tidak terjadi gangguan psikososial. Setelah pembukaan disampaikan, pengabdi membagikan pertanyaan pre-test yang berkaitan dengan stunting, kemudian dilanjutkan dengan menyampaikan informasi yang berhubungan dengan stunting, cara pencegahan, cara mengatasi, dampak terjadinya stunting dan upaya diversifikasi makanan agar kebutuhan gizi anak terpenuhi. Selama pelaksanaan penyuluhan, para peserta nampak menyimak sambil sesekali memperhatikan anaknya yang sedang bermain. Pengabdi menggunakan alat bantu dan media saat menyampaikan materi penyuluhan. Peserta diberi kesempatan untuk mengajukan pertanyaan atas beberapa materi yang kurang dipahami. Pada sesi terakhir, peserta mendapatkan contoh cara menyediakan makanan sesuai kebutuhan anak agar nilai kecukupan gizinya terpenuhi. Banyak pertanyaan yang diajukan terkait cara mengolah dan menyajikan makanan bagi anak.

Pada tahap evaluasi, pengabdi memberikan pertanyaan singkat setelah penyuluhan berakhir sebagai bentuk post-test sebagai upaya untuk mengukur keberhasilan penyampaian informasi yang telah dilaksanakan sebelumnya. Setelah post test selesai, pengabdi membagikan makanan kepada peserta, untuk dikonsumsi oleh anaknya bersama-sama di ruang pertemuan. Seluruh peserta tampak sangat antusias memberikan makanan pada anaknya sembari berjanji untuk membuat variasi dalam pengolahan maupun penyajian makanan bagi keluarganya. 


\section{Journal of Community Engagement in Health}

http://jceh.org

ISSN: 2620-3758 (print); 2620-3766 (online)

\section{HASIL}

Berdasarkan pelaksanaan penyuluhan dapat disampaikan hasilnya yaitu: meningkatnya pemahaman ibu tentang stunting. Sebelum pelaksanaan penyuluhan, pencapaian pemahaman ibu mengenai definisi, penyebab dan akibat stunting serta penentuan, pengolahan dan penyajian makanan yang tepat bagi anak, rata-rata nilai 26 dan setelah pelaksanaan penyuluhan, terjadi peningkatan nilai menjadi 69.Berikut ini tabel rata-rata nilai pemahaman peserta saat sebelum dan setelah pelaksanaan penyuluhan.

Tabel 1. Rata-rata nilai pemahaman peserta sebelum dan setelah pelaksanaan penyuluhan

\begin{tabular}{llcc}
\hline No. & \multicolumn{1}{c}{ Pertanyaan } & \multicolumn{2}{c}{ Rata-rata nilai } \\
\cline { 3 - 4 } & & $\begin{array}{c}\text { Sebelum } \\
\text { penyuluhan }\end{array}$ & $\begin{array}{c}\text { Setelah } \\
\text { penyuluhan }\end{array}$ \\
\hline 1. & Definisi stunting & 50 & 75 \\
\hline 2. & Penyebab stunting & 20 & 70 \\
\hline 3. & Gangguan psikososial akibat stunting & 10 & 60 \\
\hline 4. & Kebutuhan kecukupan gizi anak & 20 & 70 \\
\hline 5. & Penyajian nutrisi bagi anak & 30 & 70 \\
\hline & Total & 26 & 69 \\
\hline
\end{tabular}

Selanjutnya disampaikan foto kegiatan selama pelaksanaan kegiatan pengabdian kepada masyarakat ini.

Foto 1. tampilan menu makanan

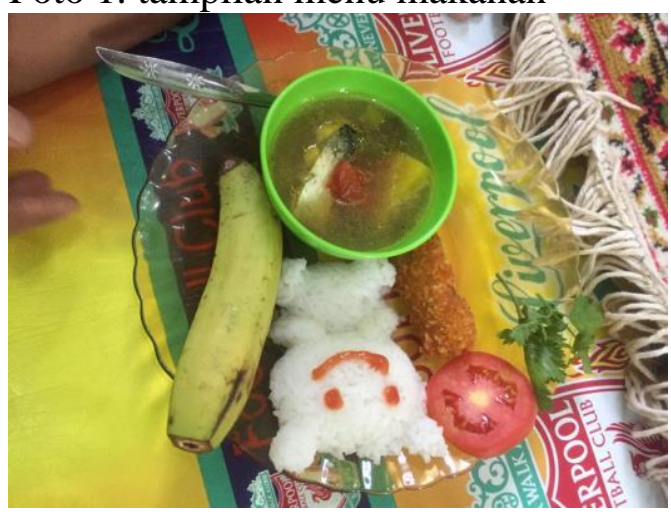

Foto 3. Pelaksanaan penyuluhan

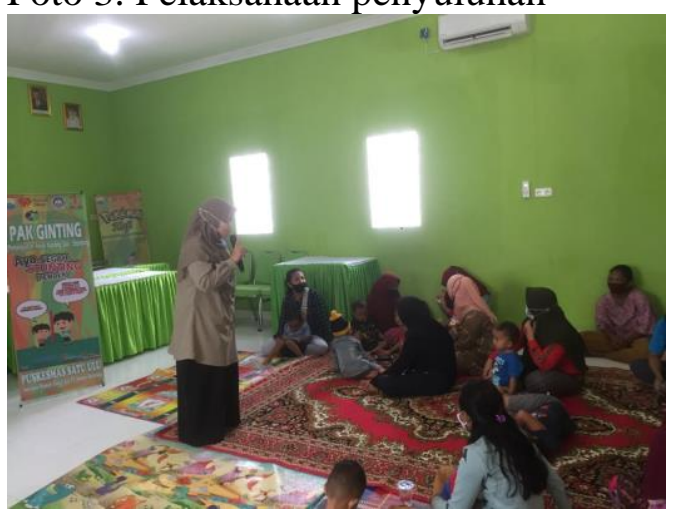

Foto 2. Tampilan anak stunting

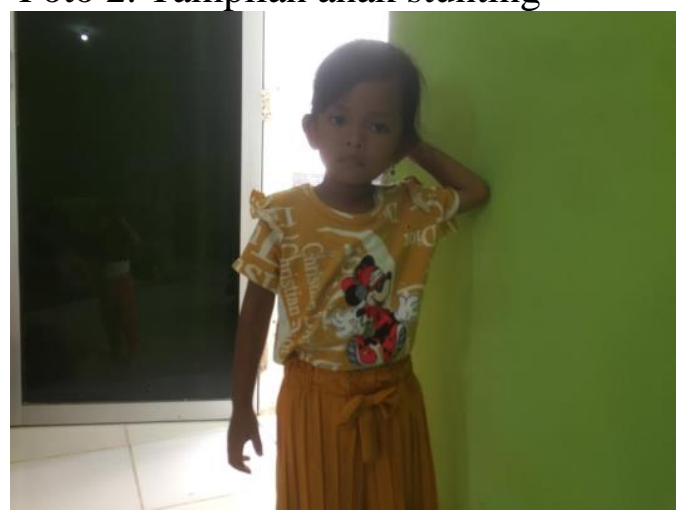

Foto 4 Saat ibu mendampingi anak

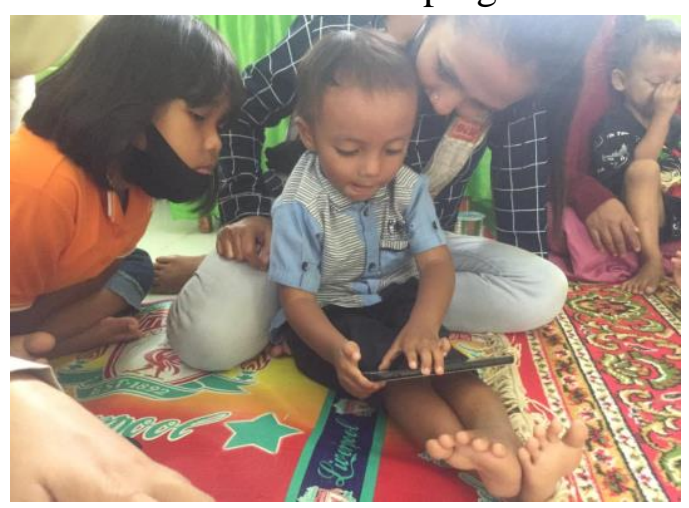




\section{PEMBAHASAN}

Beberapa faktor risiko telah ditemukan terkait dengan disfungsi psikososial dalam remaja stunting seperti jenis kelamin, pendidikan ibu dan ayah yang lebih rendah, kurangnya pendapatan keluarga dan kemiskinan (Wille et al., 2008). Tingkat pendidikan orang tua yang rendah dan kemiskinan dapat membahayakan kesehatan psikososial yang terjadi ketika anak memasuki usia remaja melalui paparan berbagai kesulitan, dan ini mungkin termasuk stres orang tua, kurangnya kehangatan dan cinta (Costello et al., 2001). Terjadinya disfungsi psikososial dapat disebabkan oleh faktor internal dan eksternal faktor. Faktor internal berasal dari diri sendiri, perasaan yang berbeda dari orang lain dan keinginan untuk memiliki tinggi badan yang baik dan proporsional. Dengan faktor internal ini, terhambat remaja memiliki harga diri yang rendah dan rentan terhadap depresi. Faktor eksternal berasal dari lingkungan yang terstigma hingga remaja yang stunting. Faktor keluarga yang mempengaruhi remaja adalah pola hubungan orang tua dengan anak, kelas sosial dan status ekonomi (Erling, 2004; Wille et al., 2008). Anak stunting secara fisik lebih lemah daripada yang lain menyebabkan perlindungan yang berlebihan dari orang tua. Ini adalah prediktor kuat dari viktimisasi dari teman-teman pada usia yang sama (Voss \& Sandberg, 2004).

Meski masih belum sepenuhnya dipahami, tiga jalur utama telah diidentifikasi bahwa gizi buruk dapat mempengaruhi perkembangan anak. Pertama, kekurangan nutrisi dapat menyebabkan kerusakan struktural dan fungsional pada otak, terutama di tahun-tahun awal kehidupan seorang anak ketika otak cepat perkembangan terjadi; kedua, anak-anak yang kekurangan energi menarik diri dan kurang terlibat dengan lingkungan mereka, mempengaruhi bagaimana mereka belajar; dan ketiga, pengasuh atau guru mungkin memperlakukan lebih kecil anak-anak secara berbeda, menantang mereka kurang dari yang mungkin sesuai untuk usia mereka (Brown \& Pollitt, 1996).

Dalam kegiatan pengabdian ini, ibu difokuskan untuk ditingkatkan pengetahuannya, karena ibu sering berinteraksi dengan anak dan menjadi penentu penyediaan kebutuhan nutrisi bagi anak. Peningkatan pemahaman ibu menunjukkan motivasi dan antusiasnya para ibu untuk meningkatkan pertumbuhan dan perkembangan anaknya sehingga terhindar dari gangguan psikososial. kader untuk memahami dan secara tidak langsung menggambarkan keinginannya untuk membantu penderita dan keluarganya. Peningkatan kemampuan dalam merawat penderita, yang diperlihatkan kader melalui demonstrasi cara merawat saat pelaksanaan penyegaran mengindikasikan itikad baik untuk menolong serta membantu dengan sepenuh hati.

Media yang digunakan saat penyuluhan menentukan keberhasilan peningkatan pemahaman partisipan mengenai stunting. Salah satu penentu keberhasilan sebuah penyuluhan adalah alat bantu yang dimanfaatkan ketika penyuluhan berlangsung. Media audiovisual berdampak positif yang lebih baik daripada media lainnya (Brown \& Pollitt, 1996). Pimpinan puskesmas serta pengelola yang memberikan dukungan penuh sangat menentukan keberhasilan penyuluhan, sehingga kegiatan pengabdian ini terlaksana sesuai perencanaan.

\section{KESIMPULAN}

Gangguan psikososial dapat terjadi pada anak akibat stunting yang dideritanya. Anak merupakan masa depan bangsa, sehingga orang tua memiliki urgensi dalam mengoptimalkan peningkatan pertumbuhan dan perkembangannya agar stunting dapat dicegah dan keterlambatan yang sudah terjadi dapat segera diupayakan solusinya. Usia emas anak tidak akan pernah kembali, kolaborasi pengawasan pertumbuhan dan perkembangan anak secara lintas sektoral, antara puskesmas, kader kesehatan, pemerintah 


\section{Journal of Community Engagement in Health}

http://jceh.org

https://doi.org/10.30994/jceh.v4i2.238

ISSN: 2620-3758 (print); 2620-3766 (online)

Vol. 4 No 2. Sep 2021. Page. 269-274

setempat dan orang tua harus dimaksimalkan. Penyuluhan bermanfaat dalam mengoptimalkan pengetahuan dan kemampuan ibu dalam mencegah, mengantisipasi, ataupun mengatasi secara bertahap jika stunting pada anak telah terjadi.

\section{REFERENSI}

Brown, J. L., \& Pollitt, E. (1996). Malnutrition, poverty and intellectual development. Scientific American, 274(2), 38-43. https://doi.org/10.1038/scientificamerican0296-38

Costello, E. J., Keeler, G. P., \& Angold, A. (2001). Poverty, race/ethnicity, and psychiatric disorder: A study of rural children. American Journal of Public Health, 91(9), 14941498. https://doi.org/10.2105/AJPH.91.9.1494

Erling, A. (2004). Why do some children of short stature develop psychologically well while others have problems? European Journal of Endocrinology, 151(SUPPL. 1). https://doi.org/10.1530/eje.0.151S035

Himaz, R. (2018). Stunting later in childhood and outcomes as a young adult: Evidence from India. World Development, 104, 344-357. https://doi.org/10.1016/j.worlddev.2017.12.019

Kemenkes RI. (2016). Situasi Balita Pendek Di Indonesia. Kementerian Kesehatan Republik Indonesia, $1-10$. https://pusdatin.kemkes.go.id/resources/download/pusdatin/infodatin/situasi-balitapendek-2016.pdf

Lee, J. M., Appugliese, D., Coleman, S. M., Kaciroti, N., Corwyn, R. F., Bradley, R. H., Sandberg, D. E., \& Lumeng, J. C. (2009). Short stature in a population-based cohort: Social, emotional, and behavioral functioning. Pediatrics, 124(3), 903-910. https://doi.org/10.1542/peds.2008-0085

Mithyantha, R., Kneen, R., McCann, E., \& Gladstone, M. (2017). Current evidence-based recommendations on investigating children with global developmental delay. Archives of Disease in Childhood, 102(11), 1071-1076. https://doi.org/10.1136/archdischild2016-311271

Picauly, I., \& Toy, S. M. (2013). Analisis Determinan Dan Pengaruh Stunting Terhadap Prestasi Belajar Anak Sekolah Di Kupang Dan Sumba Timur, Ntt. Jurnal Gizi Dan Pangan, 8(1), 55. https://doi.org/10.25182/jgp.2013.8.1.55-62

Schneider, N. Y., \& Gurovich, Y. (2017). Journal of. 6(March), 59-83.

Valla, L., Wentzel-Larsen, T., Hofoss, D., \& Slinning, K. (2015). Prevalence of suspected developmental delays in early infancy: Results from a regional population-based longitudinal study. BMC Pediatrics, 15(1), 1-9. https://doi.org/10.1186/s12887-0150528-z

Voss, L. D., \& Sandberg, D. E. (2004). The psychological burden of short stature: Evidence against. European Journal of Endocrinology, 151(SUPPL. 1), 29-33. https://doi.org/10.1530/eje.0.151S029

Wille, N., Bettge, S., \& Ravens-Sieberer, U. (2008). Risk and protective factors for children's and adolescents' mental health: Results of the BELLA study. European Child and Adolescent Psychiatry, 17(SUPPL. 1), 133-147. https://doi.org/10.1007/s00787-0081015-y 